\title{
Impact of Distributed Generation in Distribution Network Losses and Voltage Profile
}

\author{
Prahlad Pokharel, Prof. Dr. Laxman Poudel
}

\begin{abstract}
This paper presents the impacts of installing DG on a distribution circuit. The work is focused on analyzing the impact of DG installation on distribution network operation including voltage analysis and electric losses of the system. Different DG penetration levels, locations and the impacts of installing one large-scale DG on the main distribution line and distributing it several locations on voltage profile and losses are explored. IEEE 34 node test feeder and Nagarkot feeder of Bhaktapur distribution system was built using its one-line diagram in DIgSILENT PowerFactory 2017 to perform detailed analysis.

The research involves several case studies that explore the impacts of installing distributed generation (DG) on a distribution network operation including the voltage profile and losses of the system. Wind Turbine Generators are introduced as Distributed Generators (DGs) at various nodes and the impacts that DG produces on power losses and voltage profile is studied. Simulated results obtained using load flow are presented and discussed.
\end{abstract}

Index Terms - Voltage Profile, Losses, Distribution System, DG Penetration.

\section{INTRODUCTION}

Distributed generation (DG) is an approach that employs small-scale technologies to produce electricity close to the end users of power. DG technologies often consist of modular (and sometimes renewable-energy) generators, and they offer a number of potential benefits. In many cases, distributed generators can provide lower-cost electricity and higher power reliability and security with fewer environmental consequences than can traditional power generators. The electricity marketplace is undergoing a tremendous transformation as it moves towards a more competitive environment. The 'growing pains' of this transformation price instability, an ageing infrastructure, changing regulatory environments - are causing both energy users and electric utilities to take another look at the benefits of distributed generation.

One of the greatest and the most obvious problem that Nepal and the other developing countries are facing today is the increasing demand of electricity and its poor supply. The rising gap between demand and supply of electricity is the major factor of concern to developing countries like Nepal. At the same time, customers often suffer from poor power quality such as variations in voltage or electrical flow that results from a variety of factors, including poor switching

Prahlad Pokharel, Dept. of Mechanical Engineering Institute of Engineerng Pulchowk Campus, TU Pulchowk, Lalitpur

Prof. Dr. Laxman Poudel, Dept. of Mechanical Engineering Institute of Engineering Pulchowk Campus, TU Pulchowk, Lalitpur operations in the network, voltage dips, interruptions, transients, and network disturbances from loads. The DG can be placed at several locations depending upon the network to address these issues. Overall, DG proponents highlight the inefficiency of the existing large-scale electrical transmission and distribution network. Properly coordinated DG can improve the voltage profile of the system and enhance the power system stability. Placing the DG at optimal location can reduce the losses on the feeder. With the growing use of DG, it is critical to study its impacts on the distribution system operation.

The power system is prone to failures and disturbances due to weather related issues, accidents, human errors etc. Having the DG as a backup source ensures the reliability of power supply which is critical to business and industry. The overall reliability of the system can be improved. One of the main advantages of DG is their close proximity to the customer loads they are serving. DG can play an important role in improving the reliability of the current grid, reducing the losses, providing voltage support and improving power quality. The major obstacle for the distributed generation has been the high cost. However, the costs have decreased significantly over the past 20 years. The distributed generation also reduces greenhouse gas emission addressing pollutant concerns by providing clean and efficient energy. Distributed generation is the key to meeting growing demands of electricity and provides benefits to customers, utility and market.

Interconnecting a DG to the distribution feeder can have significant effects on the system such as power flow, voltage regulation, reliability etc. A DG installation changes traditional characteristics of the distribution system. Most of the distribution systems are designed such that the power flows in one direction. The installation of a DG introduces another source in the system. When the DG power is more than the downstream load, it sends power upstream reversing the direction of power flow and at some point between the DG and substation; the real power flow is zero due to back flow of power from DG.

The DG installation can impact the overall voltage profile and losses of the system. Inclusion of DG can improve feeder voltage of distribution networks in areas where voltage dip or blackouts are of concern for utilities.

\section{Methodology}

\section{A.Model Building}

In this thesis, the IEEE 34 node test feeder is used as

Test feeder. Modelling of IEEE 34 node test feeder and Nagarkot feeder of Bhaktapur distribution system is carried out on DigSilent Power Factory. 
The IEEE 34 node test feeder shown in figure 1 is an actual feeder located in Arizona and characterised by long, lightly loaded, multiple three and single phase laterals and unbalanced distribution feeder with a total load of $1769 \mathrm{~kW}$ and 1044 Mvar and two different operating voltages of 24.9 $\mathrm{kV}$ and $4.16 \mathrm{kV}$. The test feeder is modeled using the DIgSILENT Power Factory simulation package

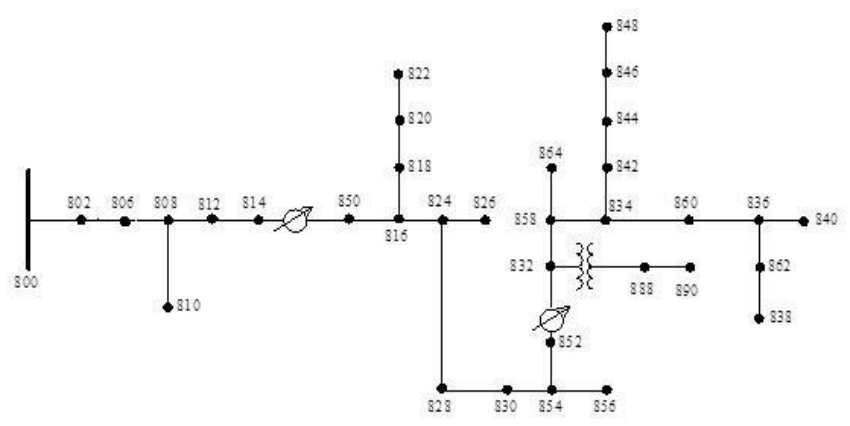

Fig 1: IEEE 34 Node Test Feeder

\section{A.1 Modelling of IEEE 34 node test feeder}

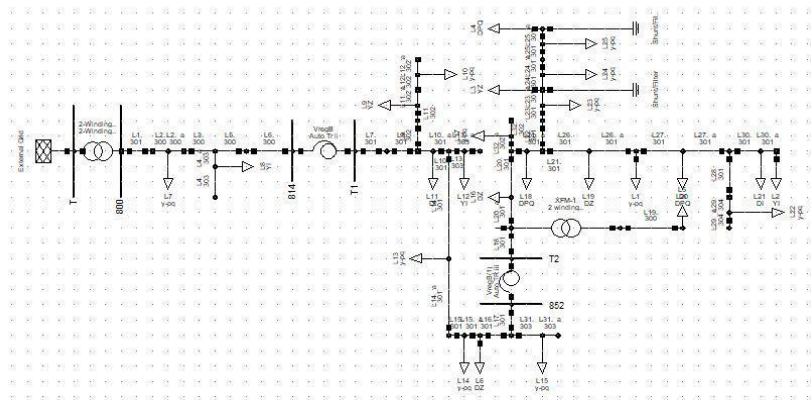

Fig 2: DIgSILENT PowerFactory Model of IEEE 34 node test feeder

The following assumptions are made during the modelling of IEEE 34 node test feeder:

1. The unbalanced phase loads in each three phase sections are summed up and taken as total three phase balanced loads.

2. The impedances for the main feeder are considered as only positive sequence impedances and all the loads were replaced by their equivalent balanced three phase loads.

Table 1. Comparison between IEEE results and Power Factory results

\begin{tabular}{|l|l|l|l|}
\hline Output Result & $\begin{array}{l}\text { IEEE } \\
\text { system data }\end{array}$ & $\begin{array}{l}\text { Power } \\
\text { Factory }\end{array}$ & $\begin{array}{l}\text { Difference } \\
(\%)\end{array}$ \\
\hline kW Loss & 273.04 & 270 & -1.11 \\
\hline $\begin{array}{l}\text { Minimum } \\
\text { average } \\
\text { voltage, p.u. }\end{array}$ & $\begin{array}{l}0.9193 \text { at } \\
\text { node } 890\end{array}$ & $\begin{array}{l}0.916 \text { at } \\
\text { node } 890\end{array}$ & -0.3589 \\
\hline $\begin{array}{l}\text { Maximum } \\
\text { average } \\
\text { voltage, p.u. }\end{array}$ & $\begin{array}{l}1.05 \text { at node } \\
800\end{array}$ & $\begin{array}{l}1.049 \text { at } \\
\text { node } 800\end{array}$ & -0.0952 \\
\hline
\end{tabular}

However, the Kvar loss was found larger about 550 Kvar than the IEEE result which is 34.99 Kvar. The cause of large difference in the reactive power loss compared to the IEEE results for the no DG case is the substation transformer. This transformer was included in the DIgSILENT PowerFactory results, but it is excluded in the IEEE results. Also, Voltage regulator were modelled as three phase autotransformer which also contributes to this reactive power loss.

\section{Scenario Description}

The penetration level of distributed generation (DG) on the distribution network is measured against total load demand or the percentage of DG power referred to the rated power of the network. The impact of penetration level is observed by installing the DGs at two different weak nodes of the network. Node 890 and 852 are identified as weakest points of the network where the system voltage is low. Node 890 experiences the lowest per unit (p.u.) voltage because it is the heavily loaded node and high voltage drop in that low voltage branch due to high current. Threee different scenarios are performed. The impact is evaluated by varying the penetration ratio as $10 \%$ and $20 \%$.

\section{(a) Scenario 1: DG at node 890}

The installation of DG at the lowest voltage location:

1a) DG Size: $10 \%$ of total feeder load

1b) DG Size: $20 \%$ DG of total feeder load

The lowest voltage location is determined by running the power flow. Node 890 experiences the lowest voltage. So Node 890 is chosen for DG installation. Therefore, the sizes of DG to be installed at this location are: $176.9 \mathrm{~kW}(10 \%)$ and $353.8 \mathrm{~kW}(20 \%)$

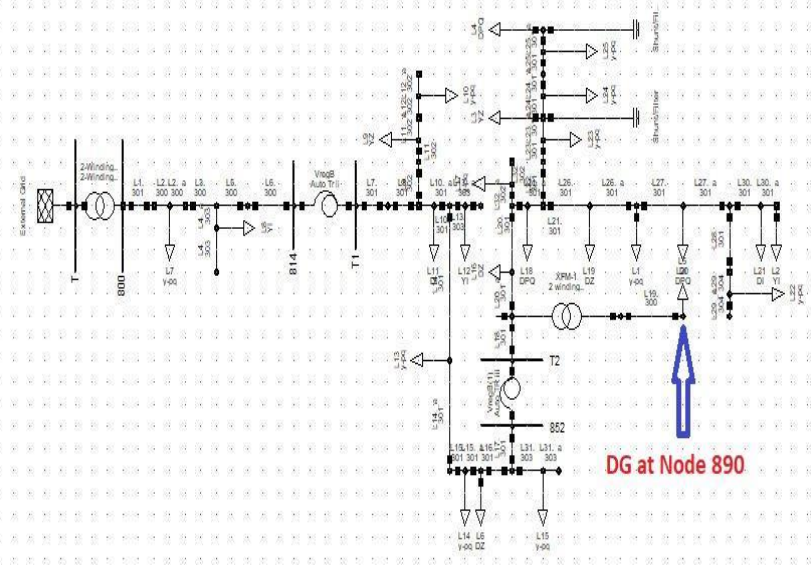

Fig 3: DG at lowest voltage location node 890

\section{(b) Scenario 2: DG at node 852}

Similarly, DG is also installed at another weak node 852:

2a) DG Size: $10 \%$ DG of total feeder load

2b) DG Size: $20 \%$ DG of total feeder load

The sizes of DG to be installed at this location are: $176.9 \mathrm{~kW}$ $(10 \%)$ and $353.8 \mathrm{~kW}(20 \%)$

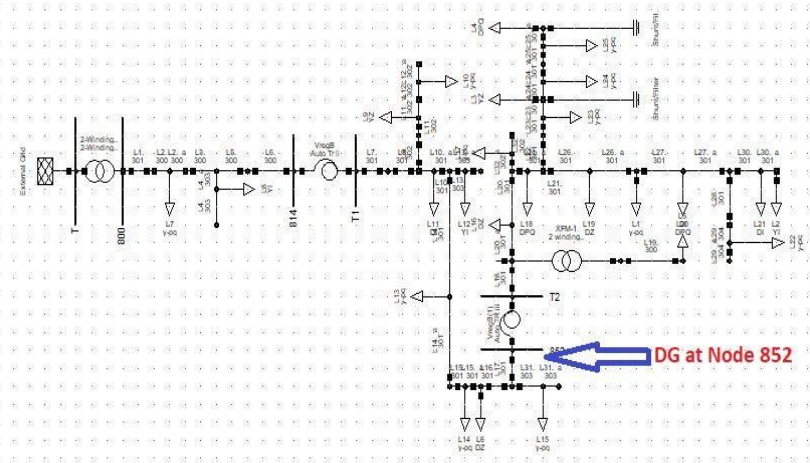

Fig 4: DG at node 852 
(c) Scenario 4: Impact of sitting

Impact of sitting is analysed by placing DGs individually one by one at other junction nodes $808,816,854,832,834$ and 840 (where laterals are branching out) assuming constant $20 \%$ penetration.

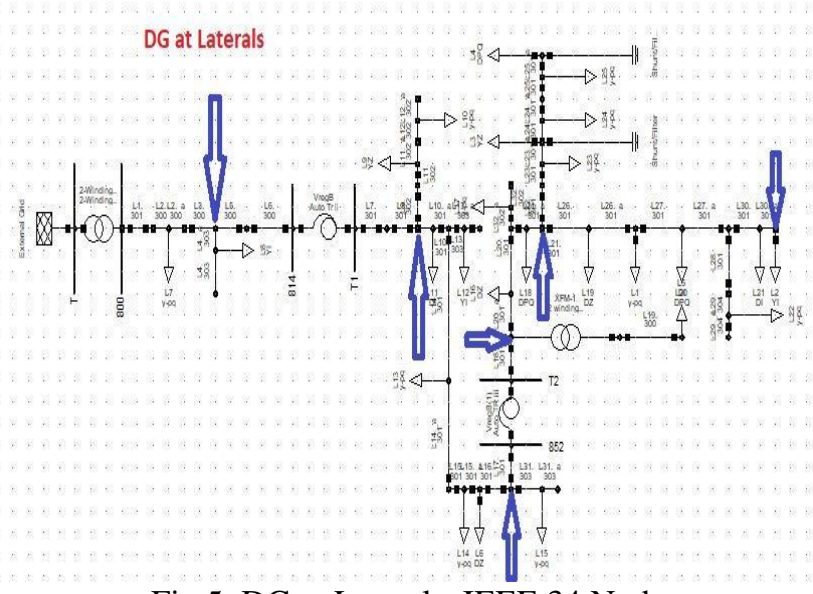

Fig 5: DG at Laterals, IEEE 34 Node

\section{Voltage Analysis}

\section{(a) Scenario 1: DG at node 890}

The end of lateral $832-890$ is the only one in the network supplied by a $24.9 / 4.16 \mathrm{kV}$ transformer, the base case profile in figure 4.6 is indicative of a heavily loaded load centre and the sloping profile is typical. Node 890 experiences the lowest per unit (p.u.) voltage because it is the heavily loaded node and high voltage drop in that low voltage branch due to high current. The voltage profile without DG penetration (Fig. 4.6) indicates that it is decreasing over the network length. As DG injects real power at the point of DG installation, the distribution System voltage improves as the size of DG increases as shown in the figure 4.6 but the voltage of Node 800,802 , and 806 was more than 1.05 p.u. in both cases. The current required to serve the spot load caused enough of a voltage drop across the line between 888 and 890 to create under voltage at 890 . The addition of DG at node 890 to address this under voltage reduced the branch current flowing in the lateral and the branch current in the vicinity of three nodes closest to the substation decreased thereby creating voltage greater than 1.05 p.u. for those three nodes.

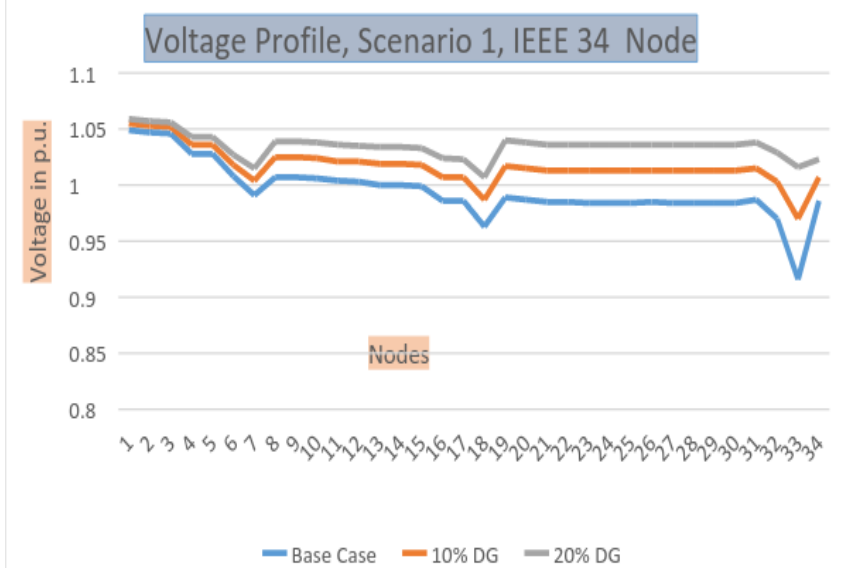

Fig 6: Voltage Profile, DG at node 890 (b) Scenario 2: DG at node 852

This is the second weakest node in the circuit. As DG injects real power at node 852 , we can see that voltage Profile goes on improving as penetration level increases. This is because as penetration level increases in this node, there is reduction in reactive power loss due to which voltage profile gets improved.

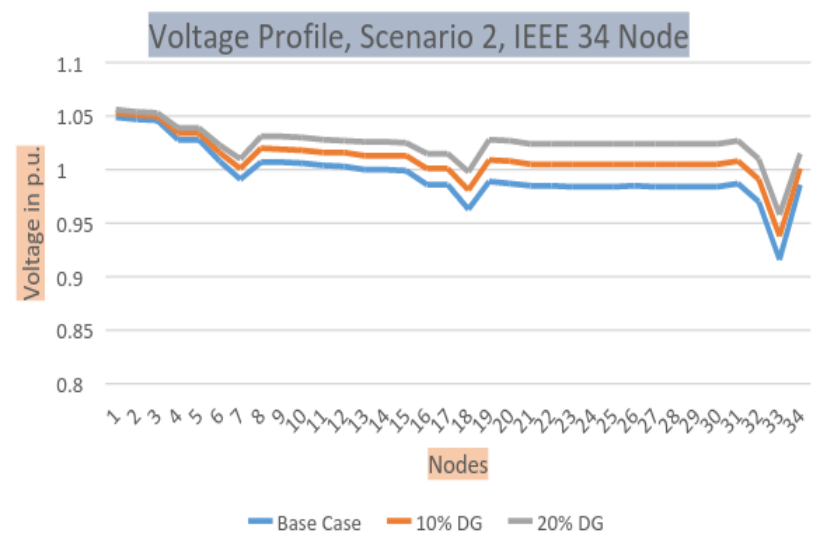

Fig 7: Voltage Profile, DG at node 852

Comparison between Scenario 1 and Scenario 2:

Placing a DG at node 852 produced voltages more than 1.05 $\mathrm{pu}$ at the same three nodes, but did not correct the under voltage at node 890 in case of $10 \%$ DG. However when $20 \%$ DG is placed, the voltage at node 890 just reached to 0.95 p.u. In between Scenario 1 and Scenario 2, we can see that voltage profile is better in scenario 1 , when DG is injected at low voltage node i.e. node 890 . Thus we can say that voltage profile is better when DJ is injected at low voltage location rather than any other location.

\section{(d) Scenario 3: Impact of sitting}

Impact of sitting is analysed by placing DGs individually at other junction nodes $808,816,854,832,834$ and 840 (where laterals are branching out) assuming constant $20 \%$ penetration. It is seen that voltage profile is improving as distance of DG penetration increases towards the end. This is because initially voltage was decreasing over the network length. As DG injects real power at different locations towards the end, the distribution System voltage goes on improving as shown in the figure 8 .

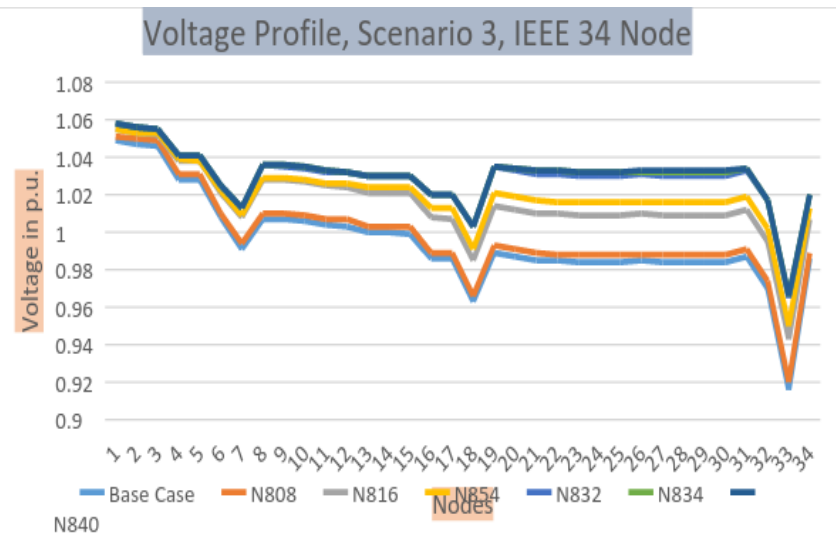

Fig 8: Voltage Profile, Impact of sitting, IEEE 34 Node 
(e) Summary:

The summary of lowest node voltage (890) in each case after DG penetration is as follows:

Table 2. Voltage at node 890 after installing DG

\begin{tabular}{|l|l|l|}
\hline & Power Injected (kW) & $\begin{array}{l}\text { Voltage at } \\
\text { Node } 890 \\
\text { (p.u.) }\end{array}$ \\
\hline Base & None & 0.916 \\
\hline $1 \mathrm{a}$ & $10 \%$ DG at node 890 & 0.97 \\
\hline $1 \mathrm{~b}$ & $20 \%$ DG at node 890 & 1.016 \\
\hline $2 \mathrm{a}$ & $10 \%$ DG at node 852 & 0.938 \\
\hline $2 \mathrm{~b}$ & $20 \%$ DG at node 852 & 0.958 \\
\hline $3 \mathrm{a}$ & $20 \%$ DG at node 808 & 0.92 \\
\hline $3 \mathrm{~b}$ & $20 \%$ DG at node 816 & 0.943 \\
\hline $3 \mathrm{c}$ & $20 \%$ DG at node 854 & 0.95 \\
\hline $3 \mathrm{~d}$ & $20 \%$ DG at node 832 & 0.965 \\
\hline $3 \mathrm{e}$ & $20 \%$ DG at node 834 & 0.966 \\
\hline $3 \mathrm{f}$ & $20 \%$ DG at node 840 & 0.966 \\
\hline
\end{tabular}

Thus, rating and location of DG unit affects the node voltage. Larger DG size contributes to increased source of active power which improves the voltage profile throughout the distribution network. It is observed that a more uniform voltage profile along the distribution feeder is achievable if the DG is supplying a large percentage of the required demand. Voltage Profile is better when DG is installed towards the end of the line. Voltage profile is best when installed at lowest voltage location. However, there is limit on the size of DG that can be injected depending upon the network so that the over voltage doesn't occur. However there is a possibility of voltage rise if the DG penetration level is too high.

\section{System Loss Analysis}

\section{(a) Scenario 1: DG at node 890}

The line losses in the distribution system are due to resistance of the overhead lines and underground cables. As the DG capacity increases the power flow from the grid to the distribution network reduces to meet the demand and hence the total losses decreased. In this scenario, the DG injects real power at the lowest voltage location at the node 890 and the system loss decreases because power flow reduces from the grid as DG serves the part of the load and hence loss decreases.

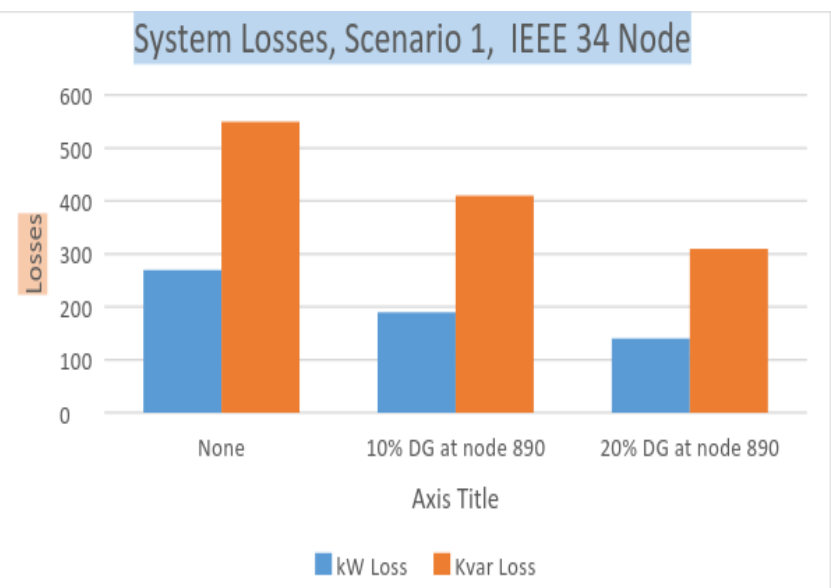

Fig 9: System Losses, Scenario 1, IEEE 34 Node

\section{(b) Scenario 2: DG at node 852}

In this scenario, the DG injects real power at the node 852 and the system loss decreases but the loss reduction is less than that of Scenario 1.

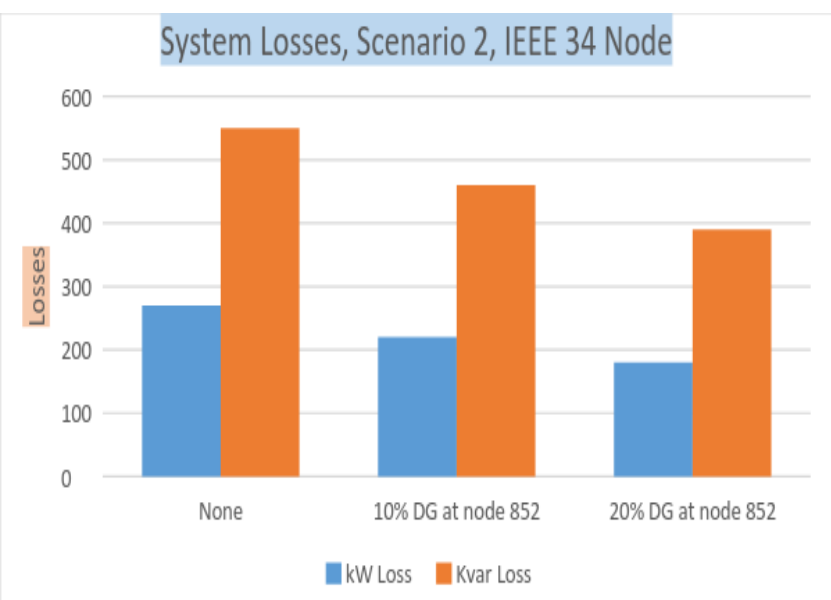

Fig 10: System Losses, Scenario 2, IEEE 34 Node

\section{Comparison between Scenario 1 and Scenario 2}

This decrease in power loss by adding DG makes sense, since for the base case any current supply to loads that are far away from the substation must come from the substation and hence pass through many line segments, whereas a DG closer to the downstream loads allow for a shorter current path and thus lower loss. From the results of scenario 1 and 2, we can conclude that the loss is minimum when DG is placed at the lowest voltage location.

\section{(c) Scenario 3: Impact of sitting}

Impact of sitting is analysed by placing DGs individually at other junction nodes $808,816,854,832,834$ and 840 (where laterals are branching out) assuming constant $20 \%$ penetration. It is seen that losses reduces significantly when DG is placed towards the end of the feeder. This is because the voltage towards the end goes on decreasing before installing DG. When DG is integrated, it helps to improve the voltage profile and serves the nearby load due to which the power flow from the grid to the distribution network reduces to meet the demand and hence the total losses goes on decreasing as the location of DG is penetrated towards the end.

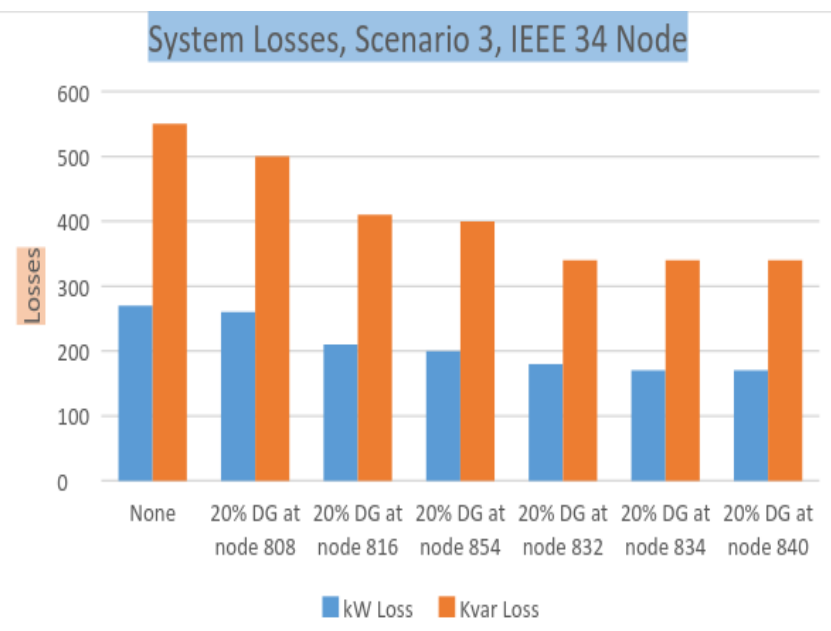

Fig 11: System Losses, Scenario 3, IEEE 34 Node 
(d) Summary

The system loss for each cases are summarised below:

Table 3: System Loss comparison, IEEE 34 Node

\begin{tabular}{|l|l|l|l|}
\hline \multirow{2}{*}{ Case\# } & Power Injected (KW) & Losses \\
\cline { 2 - 4 } & & $\mathrm{kW}$ & Kvar \\
\hline Base & None & 270 & 550 \\
\hline $1 \mathrm{a}$ & $10 \%$ DG at node 890 & 190 & 410 \\
\hline $1 \mathrm{~b}$ & $20 \%$ DG at node 890 & 140 & 310 \\
\hline $2 \mathrm{a}$ & $10 \%$ DG at node 852 & 220 & 460 \\
\hline $2 \mathrm{~b}$ & $20 \%$ DG at node 852 & 180 & 390 \\
\hline $3 \mathrm{a}$ & $20 \%$ DG at node 808 & 260 & 500 \\
\hline $3 \mathrm{~b}$ & $20 \%$ DG at node 816 & 210 & 410 \\
\hline $3 \mathrm{c}$ & $20 \%$ DG at node 854 & 200 & 400 \\
\hline $3 \mathrm{~d}$ & $20 \%$ DG at node 832 & 180 & 340 \\
\hline $3 \mathrm{e}$ & $20 \%$ DG at node 834 & 170 & 340 \\
\hline $3 \mathrm{f}$ & $20 \%$ DG at node 840 & 170 & 340 \\
\hline
\end{tabular}

All the DG locations decreased the power losses in the circuit compared to no DG scenario. This is due to supply of whole power to the loads supplied from substation (bus 800) need to flow through many branches whereas DGs closer to the loads scenario, most of the power is supplied by DGs. Thus, it can be seen that the loss is minimum when DG is placed at the lowest voltage location. Thus, Proper placement and size of DG units can have significant impact on system loss reduction.

\section{B. Nagarkot Feeder analysis}

\section{B.1 Circuit Description}

Nagarkot feeder is the longest feeder of Bhaktapur distribution system. Its total length is around $40 \mathrm{~km}$. The circuit comprises 94 transformers with total capacity of around $8608 \mathrm{KVA}$. The peak load of the feeder is $4.26 \mathrm{MW}$ which is in the month of December/January. This network comprises mainly residential customers and few industrial customers as well. This system is modelled in DIgSILENT PowerFactory as shown in figure 12 .

\section{B.2 One line diagram}

The one-line diagram of the $11 \mathrm{KV}$ Nagarkot feeder is shown in figure 12. It is modelled in DIgSILENT PowerFactory. The diagram shows the main 3 -phase $11 \mathrm{KV}$ line and the distribution laterals.

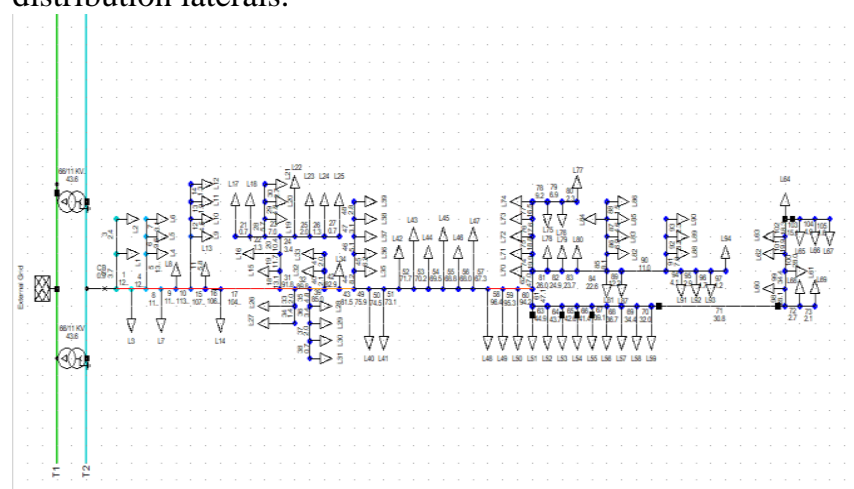

Fig 12: Single Line Diagram, Nagarkot feeder.

\section{B.3 Scenario Description}

Fourteen case studies have been conducted, which can be classified into three scenarios to illustrate the impact of size and distributed nature of DG to be installed. Scenarios 1 and 2 illustrate the impact of various DG sizes while Scenario 3 illustrates the impact of Distributing the DG at several locations on the voltage profile and losses of the system.

\section{(a) Scenario 1}

The installation of a small-scale DG of various sizes at the lowest voltage location on the main feeder:

1a) DG size: $10 \%$ of the distribution transformer load

1b) DG size: $20 \%$ of the distribution transformer load

1c) DG size: $50 \%$ of the distribution transformer load

1d) DG size: $100 \%$ of the distribution transformer load

The lowest voltage location is determined by running the power flow. At the lowest voltage location as shown in figure 13 in the distribution circuit of interest, the size of the distribution transformer is $100 \mathrm{kVA}$. The load of this transformer is $40 \mathrm{~kW}$. Therefore, the sizes of DG to be installed at this location are: $4 \mathrm{~kW}(10 \%), 8 \mathrm{~kW}(20 \%), 20 \mathrm{~kW}$ $(50 \%)$ and $40 \mathrm{~kW}(100 \%)$.

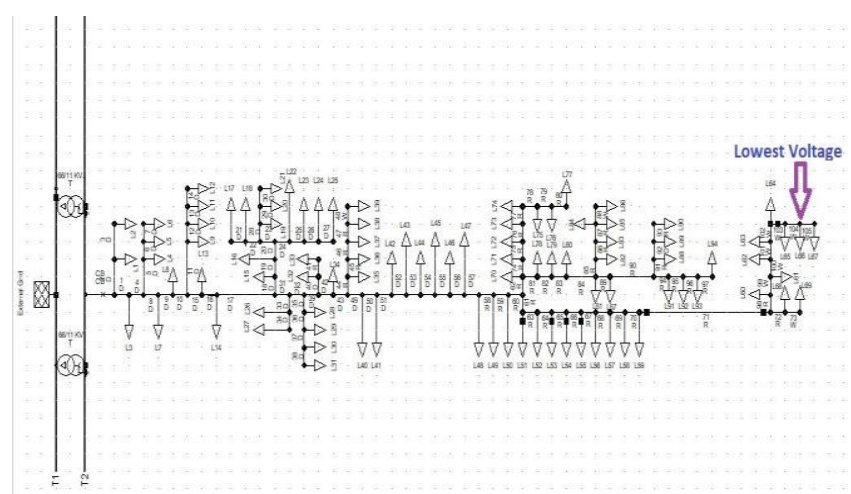

Fig 13: Lowest voltage location, Nagarkot feeder.

\section{(b) Scenario 2}

The installation of a large-scale DG of various sizes at the lowest voltage location on the main feeder:

2a) DG size: $10 \%$ of the total feeder load

2b) DG size: $20 \%$ of the total feeder load

2c) DG size: $50 \%$ of the total feeder load

2d) DG size: $60 \%$ of the total feeder load

2e) DG size: $70 \%$ of the total feeder load

2f) DG size: $100 \%$ of the total feeder load

Here, total load of the feeder is $4260 \mathrm{~kW}$. Therefore, in this scenario, the DG size would be $426 \mathrm{~kW}(10 \%), 852 \mathrm{~kW}(20 \%)$, $2130 \mathrm{~kW}(50 \%), 2556 \mathrm{~kW}(60 \%), 2982 \mathrm{~kW}(70 \%)$, and $4260 \mathrm{~kW}(100 \%)$.

\section{(c) Scenario 3}

Distributing DGs of the same size at across 5 and 10 locations of equal length on the distribution feeder:

3a) 5 DGs: each of size $426 \mathrm{~kW}$ (50\% of total feeder load)

3b) 5 DGs: each of size $852 \mathrm{~kW}$ ( $100 \%$ of total feeder load)

3c) 10 DGs: each of size $213 \mathrm{~kW}$ ( $50 \%$ of total feeder load)

3d) 10 DGs: each of size $426 \mathrm{~kW}$ ( $100 \%$ of total feeder load) 
In this scenario, two DG sizes $(50 \%$ and $100 \%$ of the total feeder load) are distributed across 5 and 10 locations of equal length as shown in figure 4.14 and 4.15 to study the impact of Distributed DG at several locations on the voltage and losses of the system.

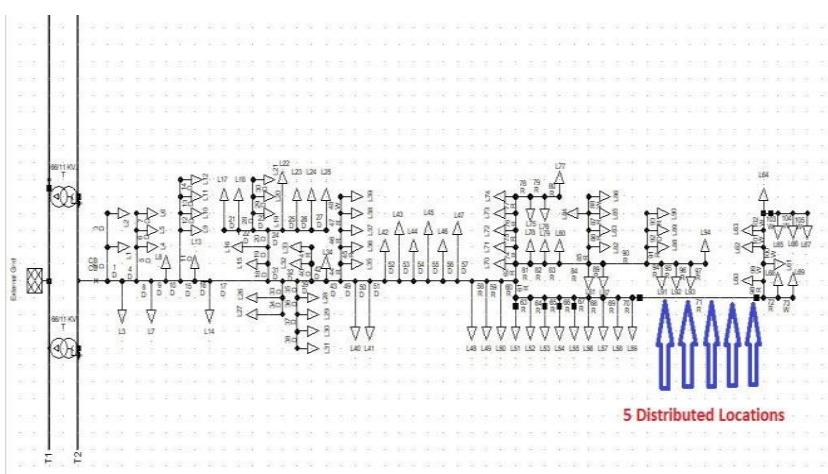

Fig 14. Five Distributed Locations, Nagarkot feeder.

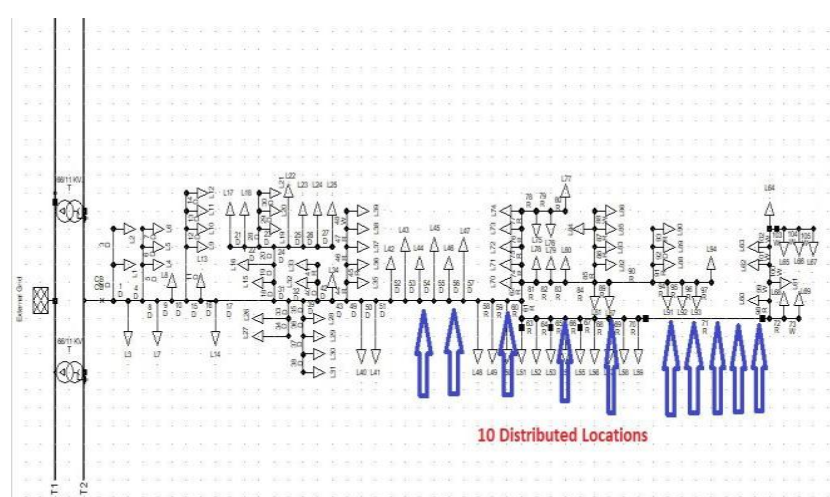

Fig 15: Ten Distributed Locations, Nagarkot feeder.

\section{Voltage Analysis}

(a) Scenario 1: Small-scale DGs

It is observed that the voltage drops linearly starting from the distribution substation to the far-end load in the distribution network under study. As a small-scale DG injects real power at the point of DG installation, the distribution System voltage improves slightly. In this scenario, since the size of the DG is very small, the voltage impact is insignificant as shown in the figure 4.16. Installing a $100 \% \mathrm{DG}(40 \mathrm{~kW})$ causes slight increase in voltage (less than 1\%) from the base case (NO DG).

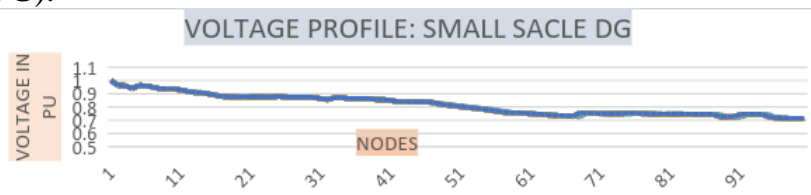

Fig 16: Voltage Profile comparison, Scenario 1, Nagarkot feeder.

\section{(b) Scenario 2: Large-scale DG}

Figure 4.19 shows that the voltage drops linearly starting from the substation to the far end load in the distribution network. As a large-scale DG injects real power at the point of DG installation, the distribution System voltage improves. The size of the DG is ranged from $426 \mathrm{~kW}$ to $4260 \mathrm{~kW}$. However, the voltage level at all the buses is higher compared to without DG connection into the system. Simulation result proves that the connected DG shares the responsibility of supplying the required demand with the substation. It is observed that a larger capacity of DG contributes to a larger part of required demand therefore increasing the voltage level in each bus compared to the scenario without DG connection.

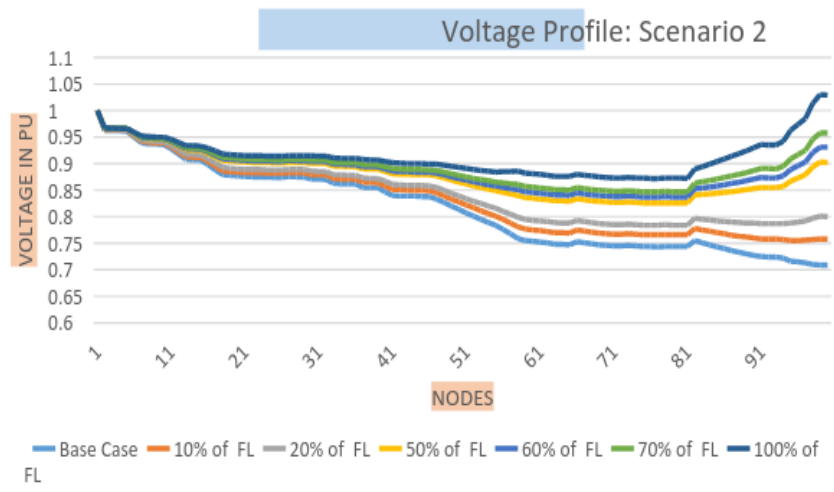

Fig 17: Voltage Profile comparison, Scenario 2, Nagarkot feeder.

\section{Result Comparison: Scenarios 1 \& 2 (Size Impact)}

In scenario 1 , the voltage impact is insignificant whereas in Scenario 2, as the penetration level of DG installed on the system is increased, the overall voltage profile is maintained. When the DG is added in terms of total system load, the overall voltage is increased as shown in the figure 4.17. The voltage of node where DG is placed is increased up to approximately $20 \%$.

\section{(c) Scenario 3: Distributed Location Impact}

In this scenario, DGs of size $50 \%$ and $100 \%$ of the total feeder load $(2130 \mathrm{~kW}-4260 \mathrm{~kW})$ are distributed across 5 and 10 locations. Distributing the DG from an aggregated location (lowest voltage) to 5 and 10 locations of equal lengths can make a positive difference to the voltage profile depending on the location and concentration of the loads. We can see from above graph that distributing 5 DGs of total feeder load each of $852 \mathrm{~kW}$ gives the better Voltage Profile at the end of the feeder whereas at the start of the feeder the voltage profile is almost same in case of 5 DG and 10 DG of $100 \%$ feeder load.

Voltage Profile: Scenario 3

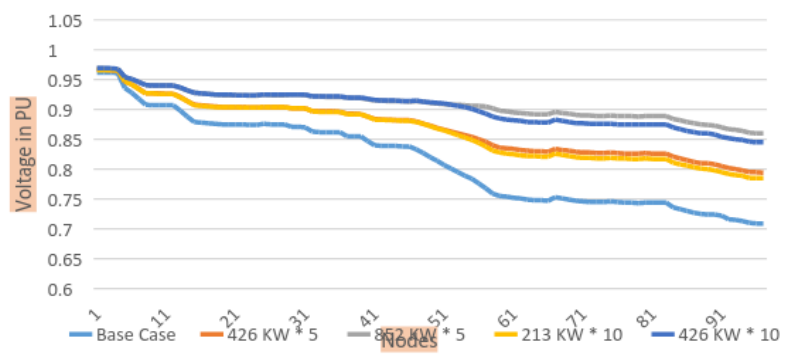

Fig 18: Voltage Profile comparison, Scenario 3, Nagarkot feeder. 


\section{(d) Summary}

Thus, DG output power supplying for a larger part of required demand is able to improve the overall voltage profile along the distribution feeder. It is observed that higher voltage level of the far-end load side of the distribution network is achievable when the DG capability is increased. The results shows that a more improved voltage profile along the feeder is achievable if the DG is capable of providing a larger percentage of the required demand in the distribution network. It is obvious that the voltage level at bus increases when DG is connected. DG's function of providing part of the required demand in the distribution network improves the voltage at the point of DG connection. The lowest voltages on each cases are summarised in the Table 4.

Table 4. Lowest Voltage after Installing DG, Nagarkot feeder

\begin{tabular}{|c|c|c|}
\hline Case\# & Power Injected & $\begin{array}{l}\text { Voltage } \\
\text { (p.u.) }\end{array}$ \\
\hline Base & None & 0.709 \\
\hline $1 \mathrm{a}$ & $4 \mathrm{Kw}$ & 0.710 \\
\hline $1 b$ & $8 \mathrm{~kW}$ & 0.710 \\
\hline $1 \mathrm{c}$ & $20 \mathrm{~kW}$ & 0.712 \\
\hline $1 d$ & $40 \mathrm{~kW}$ & 0.714 \\
\hline $2 a$ & $426 \mathrm{~kW}$ & 0.758 \\
\hline $2 b$ & $852 \mathrm{~kW}$ & 0.800 \\
\hline $2 \mathrm{c}$ & $2130 \mathrm{~kW}$ & 0.902 \\
\hline $2 \mathrm{~d}$ & $2556 \mathrm{~kW}$ & 0.931 \\
\hline $2 \mathrm{e}$ & $2982 \mathrm{~kW}$ & 0.958 \\
\hline $2 f$ & $4260 \mathrm{~kW}$ & 1.029 \\
\hline $3 a$ & $426 \mathrm{~kW} * 5$ locations & 0.794 \\
\hline $3 b$ & $852 \mathrm{~kW} * 5$ locations & 0.860 \\
\hline $3 c$ & $213 \mathrm{~kW} * 10$ locations & 0.785 \\
\hline $3 d$ & $426 \mathrm{~kW} * 10$ locations & 0.845 \\
\hline
\end{tabular}

\section{System Loss Analysis}

\section{(a) Scenario 1: Small-scale DG}

In this scenario, the small-scale DG $(4 \mathrm{~kW}-20 \mathrm{~kW})$ injects real power at the lowest voltage Locations and the system losses decrease. Due to the small size of DG, the impact is small as shown in figure 4.19. As shown in the figure, the system losses decrease from $1040 \mathrm{~kW}$ to $1020 \mathrm{~kW}$ (approx. 2\%) and from 1280 Mvar to 1260 Mvar ( approx. $1.5 \%$ ) as we install a DG of size $100 \%$ of distribution transformer load (40kW) at the lowest voltage location.

\section{Scenario 1: System Losses}

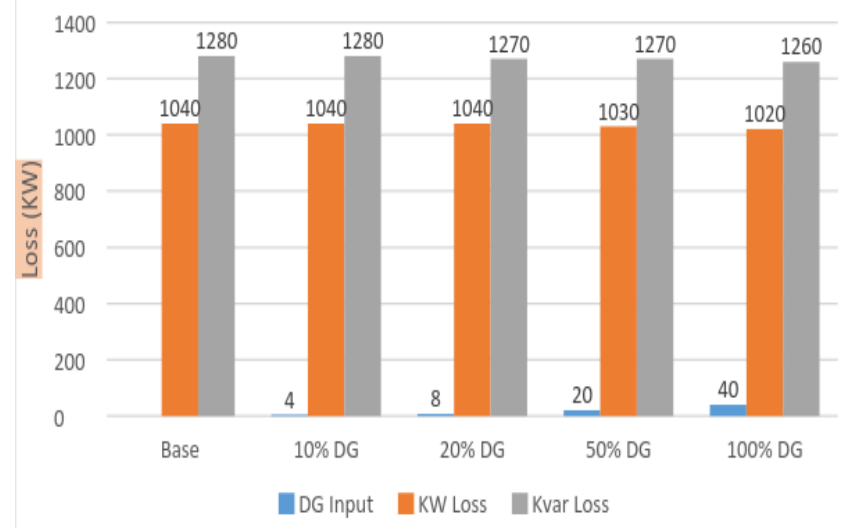

Fig 19: System Losses, Scenario 1, Nagarkot feeder

\section{(b) Scenario 2: Large-scale DG}

In this scenario, the large scale DG $(426 \mathrm{~kW}-4260 \mathrm{~kW})$ injects real power at the lowest voltage location and the systems losses reduce significantly. The results for different load penetrations are graphically shown in the figure 20 below.

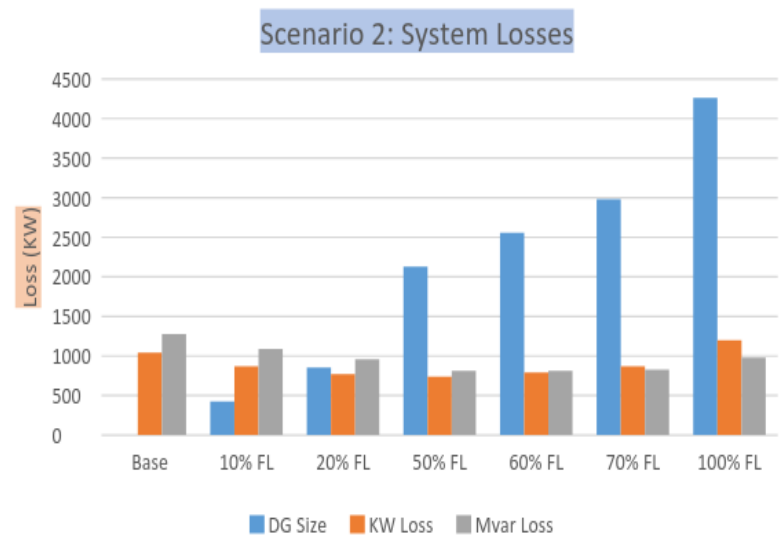

Fig 20: System Losses, Scenario 2, Nagarkot feeder

As shown in the figure above, when size of DG is $50 \%$ of total feeder load $(2130 \mathrm{~kW})$, the systems losses reduce significantly from $1040 \mathrm{~kW}$ to $740 \mathrm{~kW}(28.8 \%)$ and from 1280 Mvar to 810 Mvar (36.71\%). It is also observed that installing a $50 \%$ DG i.e. $(2130 \mathrm{~kW})$ causes more reduction of losses than adding $100 \%$ DG i.e. $(4260 \mathrm{~kW})$. This shows that the total losses vary when the DG output changes as shown in figure 20 . The losses will be minimum when the distance of all the load points to source is minimum. So, the losses decrease when DG is injected in a distribution network at a suitable location because the power flow from the grid to the distribution network reduces to meet the demand and DG serves that particular load. When the size of DG increases further the losses reduce further up to a saturation point after which DG current increases if the size of DG is increased which travel longer distance to meet the more demand. Loss increases as current travels longer distance to serve the load. It can be seen that loss increases as the size of DG increases beyond $50 \%$. This is because DG current increases further which travel longer distance to meet the demand and also the thermal limit of the line is exceeded. Loss increases after certain level of DG current as current travels longer distance to serve the load. 
(c) Scenario 3: Distributed Location Impact

In this scenario, the large-scale DG is distributed to 5 and 10 locations of equal length to study the impacts of distributing DG to several locations. Distributing the aggregated DG to 5 and 10 locations can reduces the losses as shown in figure 21 below.

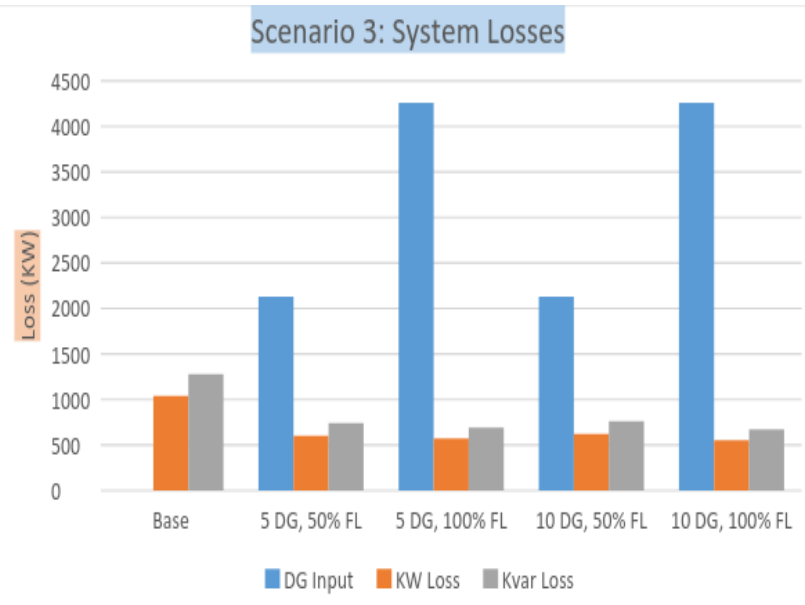

Fig 21: System Losses, Scenario 3, Nagarkot feeder

It is observed from the figure above that distributing the $100 \%$ DG $(4260 \mathrm{~kW})$ at 10 locations can reduce the losses significantly instead of installing an aggregated DG at one location. In this case, the losses reduce from $1040 \mathrm{~kW}$ to 550 $\mathrm{kW}(47 \%)$ and from $1280 \mathrm{Mvar}$ to $670 \mathrm{Mvar}$ (47\%). This result is expected because in this case multiple DG serves multiple loads at the point of installation. The distance between the source and the load is minimum in this case. Hence, there is huge reduction of losses in this case.

\section{(d) Summary}

The system losses for each cases are shown in the Table 5 below.

Table 5 System Loss comparison, Nagarkot feeder

\begin{tabular}{|l|l|l|l|}
\hline & \multicolumn{1}{|c|}{ Power Injected } & \multicolumn{2}{c|}{ Losses } \\
\hline $\begin{array}{c}\text { Case } \\
\#\end{array}$ & \multicolumn{1}{|c|}{ Kvar } \\
\hline Base & None & 1040 & 1280 \\
\hline $1 \mathrm{a}$ & $4 \mathrm{Kw}$ & 1040 & 1280 \\
\hline $1 \mathrm{~b}$ & $8 \mathrm{KW}$ & 1040 & 1270 \\
\hline $1 \mathrm{c}$ & $20 \mathrm{KW}$ & 1030 & 1270 \\
\hline $1 \mathrm{~d}$ & $40 \mathrm{~kW}$ & 1020 & 1260 \\
\hline $2 \mathrm{a}$ & $426 \mathrm{~kW}$ & 870 & 1090 \\
\hline $2 \mathrm{~b}$ & $852 \mathrm{~kW}$ & 770 & 960 \\
\hline $2 \mathrm{c}$ & $2130 \mathrm{~kW}$ & 740 & 810 \\
\hline $2 \mathrm{~d}$ & $2556 \mathrm{~kW}$ & 790 & 810 \\
\hline $2 \mathrm{e}$ & $2982 \mathrm{~kW}$ & 870 & 830 \\
\hline $2 \mathrm{f}$ & $4260 \mathrm{~kW}$ & 1200 & 980 \\
\hline $3 \mathrm{a}$ & $426 \mathrm{~kW} * 5$ locations & 600 & 740 \\
\hline $3 \mathrm{~b}$ & $852 \mathrm{~kW} * 5$ locations & 570 & 690 \\
\hline $3 \mathrm{c}$ & $213 \mathrm{~kW} * 10$ locations & 620 & 760 \\
\hline $3 \mathrm{~d}$ & $426 \mathrm{~kW} * 10$ locations & 550 & 670 \\
\hline \multicolumn{2}{|l}{} &
\end{tabular}

Thus, it can be seen that distributing the $100 \%$ DG $(4260 \mathrm{~kW})$ at 10 locations can reduce the losses significantly instead of installing an aggregated DG at one location. This is due to the fact that DG serves the load nearby with minimum current path due to which the loss reduces significantly. From above results we can conclude that there are various impacts of DG of different sizes and at different locations.

\section{CONCLUSION}

In this research, detailed analysis on some of the impacts of distributed generation (DG) on a distribution network operation is conducted.

The obtained results have shown that the DG influences the distribution network and that their precise location and size are vital in reducing power losses and improving the voltage Profile. It is noted that DG placement cannot always results to effective loss reduction i.e., it depends on the rating and location of DG unit. The results shows that up to a particular rating and location of DG unit only the maximum power loss reduction can be achieved and in some cases it leads to more power losses in the system. Therefore the implementation of DG is depends on rating, location and system power factor. DG implementation as a source of active power has a great positive impact on improving the voltage profile through the entire distribution network.

\section{ACKNOWLEDGEMENT}

The authors extend their hearty gratitude to the faculties and colleagues at Tribhuvan University, Institute of Engineering, Pulchowk Campus and engineers of Nepal Electricity Authority for their constant help, support and recommendations.

\section{REFERENCES}

[1] "Distributed Generation: It's Role in Emerging Economies", Rajat K.Sen, Chris Namovicz, Jennifer Kish- SENTECH, Inc.

[2] K. Kauhaniemi and L. Kumpulainen, "Impact of distributed generation on the protection of distribution networks," 2004 Eighth IEE International Conference on Developments in Power System Protection, 2004, pp. 315-318 Vol.1.

[3] Mario Vignolo, R. Z., "Transmission Networks or Distributed Generation?" Montevideo, Uruguay, 2002.

[4] Barker, P.P.; De Mello, R.W., "Determining the impact of distributed generation on power systems. I. Radial Distribution Systems," Power Engineering Society Summer Meeting, 2000. IEEE, vol.3, no., pp.1645-1656 vol. 3, 2000.

[5] Vu Van Thong, Johan Driesen, and Ronnie Belmans, "Interconnection of Distributed Generators and Their Influences on Power System.' International Energy Journal: Vol. 6, No. 1, Part 3, June 2005.

[6] F. Gonzalez-Longatt, C. Fortoul, "Review of Distribued Generation Concept: Attemp of Unification.” RE\&PQJ, Vol. 1, No.3, March 2005

[7] Gonzalez-Longatt, F. M., "Impacto de la Generación Distribuida en el Comportamiento de los Sistemas de Potencia", Universidad Central de Venezuela, June 2008.

[8] Favuzza, S., et al., Optimal electrical distribution systems reinforcement planning using gas micro turbines by dynamic ant colony search algorithm. Power Systems, IEEE Transactions on, 2007. 22(2): p. 580-587.

[9] Cano, E.B. Utilizing fuzzy optimization for distributed generation allocation. In TENCON 2007-2007 IEEE Region 10 Conference. 2007. IEEE. 